\title{
Development of Metal Matrix Composites by Direct Energy Deposition of 'Satellited' powders
}

\author{
P. K. Farayibi ${ }^{1 *}$, T. E. Abioye ${ }^{1,4}$, A. Kennedy ${ }^{2}$, A.T. Clare ${ }^{3}$ \\ ${ }^{I}$ Department of Industrial and Production Engineering, Federal University of Technology Akure, PMB 704, Akure, Ondo \\ State, Nigeria \\ ${ }^{2}$ Engineering Department, Lancaster University, Engineering Building, LA1 4YR, Lancaster UK \\ ${ }^{3}$ Advanced Component Engineering Laboratory (ACEL), Faculty of Engineering, University of Nottingham, Nottingham, \\ NG7 2RD, UK \\ ${ }^{4}$ Structural Materials Niche Area, School of Materials and Mineral Resources Engineering, Engineering Campus, Universiti \\ Sains Malaysia, 14300 Nibong Tebal, Penang, Malaysia
}

\begin{abstract}
Limited research has been undertaken investigating the material design freedoms that are granted through the use of additive manufacturing methods, especially the development of materials specifically formulated for additive processes. In this study, a new material combination was evaluated for use with directed energy deposition methods. Here, a Ti-6Al$4 \mathrm{~V}$ powder is processed in combination with a much finer titanium diboride powder following a satelliting procedure. The resulting combination consists of large Ti-6Al-4V particles encased in finer titanium diboride. Deposited composites exhibit TiB needles associated with increased hardness. Processing conditions are detailed which permit the deposition of the prepared feedstock onto Ti-6Al-4V substrates. Microstructural characterisation revealed that the composite was made up of eutectic TiB precipitates dispersed in $\alpha-\beta$ Ti matrix with few partially melted Ti-6Al-4V and $\mathrm{TiB}_{2}$ particles. Satelliting $\mathrm{TiB}_{2}$ powder onto Ti-6Al-4V particle surfaces has significantly improved the homogeneity of composite which is characterised with randomly oriented and uniform distribution of $\mathrm{TiB}$ needles in the microstructure. Hardness of composites ranged between $440-480 \mathrm{HV}$. Hence, the feedstock preparation method proposed has been found to be effective and can be adapted for low cost and rapid formulation of a host of materials for processing by additive manufacture.
\end{abstract}

Key Words: Ti-6Al-4V; TiB whiskers; Additive Manufacture; Metal Matrix Composite; Powder Satelliting; Direct Energy Deposition.

\footnotetext{
*Corresponding author - +2349066590609; pkfarayibi@futa.edu.ng
} 


\section{Introduction}

Additive manufacturing (AM) is growing in its acceptance and is subject to intense levels of research [1]. Directed Energy Deposition (DED) is an AM technique used for both new part manufacture and repair. Here, consolidated parts are achieved by the interaction of materials and heat, which can be generated through diverse energy sources that include laser, electron beam, ultraviolet light, and electric heaters, amongst others [2]. The metallic materials used for DED processes can be in the form of powder and wire, which can be coaxially fed or side-fed into the generated melt pool or maybe prepared as a preplaced powder layer as in powder bed fabrication (PBF) [3]. Metallic powders are of either angular or spherical morphology with suitable particle size ranges selected for flowability. The flexibility of the additive manufacturing process, in terms of material utilised, has been further demonstrated by the concurrent delivery of materials into the melt pool in the form of wire-and-powder to develop either surface coatings or functional components [4]. Owing to the freedom of materials that can be utilised in additive manufacturing processes, components and surface coatings of monolithic, metal matrix composites, and functionally graded materials can be easily created.

Metal matrix composites and functionally graded materials are developed to synergise the mechanical and thermal properties of conventional metals and reinforcement materials, mostly ceramics, to achieve composites with distinctive properties when compared to monolithic materials. These metal matrix composites are commonly designed to enhance performance, often with reduced weight, in structural, wear, and thermal management applications for space, aviation, automotive, mining, power generation and other industries $[5,6]$. Additive manufacturing techniques have been used to fabricate different metal matrix composites and functionally graded materials using materials in the form of pre-blended and preplaced powder [7], a wire-powder system [8], a powder-melt injection/blown system [9] and direct metal droplet [10]. In powder blown system, monolithic or pre- blended/simply mixed powders are continuously injected into an energy generated melt pool to fabricate part on a programmable substrate, while in wire-powder system, the materials required for fabrication of part are fed into the melt pool in the form of wire and powder, to manipulate the composition of the part. Powder-melt injection system is majorly for creation of enhanced functional surface properties, by injecting powder of materials with desired superior properties into the energy generated melt pool on the functional surface of the part. Direct metal droplet deposition fabricates parts by using uniform composition, metal microdroplets as a building block for the fabrication on a substrate which prevents considerably or eliminates microstructural segregation during melting and solidification processes $[11,12]$. Since melting takes place in the presence of the laser, reinforcement materials can be synthesised in-situ as a result of diffusion and alloying during the additive manufacturing process [130].

However, there is a need for development of the material feedstocks used for additive manufacturing especially when multiple feedstocks are to be employed. Some researchers have attempted the use of traditional ball milling process to prepare feedstock for additive manufacturing process [14]. Moreover, owing to high cost and high energy consumption, an electroless plating method was also recently adopted for the preparation of feedstock powder 
for use in selective laser melting process for production of metal matrix composites $[15,16]$. When simply mixed powders are used, there is a tendency for constituent segregation to occur during processing, particularly when there is a significant difference between the mean particle size or density of the individual constituent powders being mixed. The constituent segregation of simply mixed feedstock during laser cladding has been reported in a study [17], where the mean particle sizes of pre-blended constituents employed differed by a factor of 10. It was observed that segregation during the laser cladding of simply mixed feedstock resulted in a significant microstructural inhomogeneity in the deposited samples (Figure 1) and hence, feedstock modification and material development to address this issue is necessary.

In light of limited prior research on the formulation of materials for AM purposes, this paper presented a new methodology for the preparation of feedstock for AM processes to prevent constituent segregation during processing and promote microstructural homogeneity. This method was demonstrated using a $\mathrm{TiB}_{2} / \mathrm{Ti}-6 \mathrm{Al}-4 \mathrm{~V}$ material system to manufacture composites through the direct energy deposition process and mechanism through which the method works was presented. $\mathrm{TiB}_{2}$ is a refractory material which possesses high strength to density ratio, high hardness, low specific weight and excellent thermal and chemical stability. $\mathrm{TiB}_{2}$ is a good choice as reinforcement in Ti-6Al-4V which is the most common Ti alloy, as its reaction product such as $\mathrm{TiB}$ is preferred owing to its thermodynamic stability in Ti alloys [18]. However, this method is not restricted to the material system employed in this study; it can be adopted for compatible material systems to achieve unique material formulation to achieve the desired physical, electrical and mechanical properties in the resultant alloy.

\section{Methodology}

\subsection{Materials and Feedstock Preparation}

The Ti-6Al-4V powder used in this study was supplied by Crucible Research, USA, $\mathrm{TiB}_{2}$ powder used was supplied by Sigma Aldrich Chemical Company, UK and Ti-6Al-4V coupons $(180 \mathrm{~mm} \times 100 \mathrm{~mm} \times 5 \mathrm{~mm})$ were used as the substrate. Prior to the deposition trials, the Ti$6 \mathrm{Al}-4 \mathrm{~V}$ substrates were grit-blasted and degreased with acetone to improve laser absorptivity and remove surface contaminants respectively. While the $\mathrm{TiB}_{2}$ particles are of angular morphology, the Ti-6Al-4V powder particles have a predominantly spherical morphology. The mean particle sizes for the Ti-6Al-4V and $\mathrm{TiB}_{2}$ powders, as determined via laser diffractometry (Malvern Instruments, UK), were $100 \mu \mathrm{m}$ and $10 \mu \mathrm{m}$ respectively (see Figure 2).

A pre-blended powder containing Ti-6Al-4V (90 wt.\%) and $\mathrm{TiB}_{2}(10 \mathrm{wt} . \%)$ was prepared using a powder mixer. A representative sample of the mixture was subjected to particle size analysis, which gave a bimodal distribution as shown in Figure 2. In order to modify the feedstock to prevent constituent segregation, a method of attaching the fine $\mathrm{TiB}_{2}$ particles onto the surface of the Ti-6Al-4V particles was employed by spraying a solution of 2.7 vol.\% polyvinylalcohol (PVA) in water onto the pre-blended feedstock, which was then thoroughly homogenised in a tubular mixer to achieve "satelliting" of the small particles onto the larger ones, without clustering. The dried feedstock was subjected to characterisation by X-ray diffraction, confirming the presence of $\mathrm{TiB}_{2}$ and $\alpha$-Ti phases (Figure $2 \mathrm{~b}$ ) and examined under a scanning 
electron microscope, in secondary electron mode as shown in Figure 2a, which shows the small $\mathrm{TiB}_{2}$ particles attached to the surface of the larger Ti-6Al-4V particles. The "satelliting" of the smaller $\mathrm{TiB}_{2}$ particles onto the surface of the larger Ti-6Al- $4 \mathrm{~V}$ particles was possible owing to the adhesive properties of the PVA, which is a water- soluble synthetic polymer [19]. The tubular mixing increases the chance of having as many as possible $\mathrm{TiB}_{2}$ particles to be attached to the surface of the Ti-6Al-4V particles in which either of these particles or both have already been smeared with the adhesive PVA.

\subsection{Experimental Setup and Process Parameters}

A 2-kW ytterbium-doped, continuous wave (CW), fibre laser (IPG Photonics) operating at $1.07 \mu \mathrm{m}$ wavelength, coupled with a beam delivery system (125 mm collimating lens and a 200 $\mathrm{mm}$ focussing lens) and a Precitec YC 50 cladding head, was used. The laser beam was defocussed to give a Gaussian beam profile with a circular spot size of $3.1 \mathrm{~mm}$ for feedstock processing. The laser system was mounted on a 4 axis CNC table to traverse the Ti-6Al-4V substrate mounted on the worktable while the laser beam is kept stationary. The powder feedstock was delivered by a Model 1264 powder feeder (Praxair Surface Technologies) into the melt pool through a side feeding nozzle inclined at angle $23^{\circ}$ to the laser beam axis. A flexible chamber was used to isolate the deposition work space and was flushed with argon, for 10 minutes prior to the start of deposition and continuously flushed during the experiment at $301 . \mathrm{min}^{-1}$. Table 1 presents the processing parameters employed for the experimental trials.

\subsection{Microstructure and Hardness Evaluation}

After the $\mathrm{TiB}_{2} / \mathrm{Ti}-6 \mathrm{Al}-4 \mathrm{~V}$ feedstock was processed by DED, a $10 \mathrm{~mm}$ long composite bead from each sample was prepared using wire electrical discharge machining (WEDM). The specimens were then mounted in a conductive resin and polished to a $1 \mu \mathrm{m}$ mirror-finish. Xray diffraction (XRD) was employed to identify the phases present in the composite produced. A Siemens D500 - 1 XRD machine, operated at $40 \mathrm{kV}$ and $25 \mathrm{~mA}$ was used and phases present in the experimental spectra were identified using the International Centre Diffraction Database (ICDD). The diffraction scans were made over a $2 \theta$ range of $20-90^{\circ}$ and phases identified were labelled. A Philips XL 30 Scanning Electron Microscope (SEM), operated at $20 \mathrm{kV}$, was used to examine the microstructural features of the $\mathrm{TiB}_{2} / \mathrm{Ti}-6 \mathrm{Al}-4 \mathrm{~V}$ composites. The microstructural examination was conducted in both secondary electron (SE) and backscattered electron (BSE) modes to identify all phases formed in the composite and their features. Prior to SEM examination, samples were etched with Kroll's reagent to reveal the composite microstructure. The composite hardness was evaluated with the aid of a Breuher Microhardness Tester. A load of $2.94 \mathrm{~N}$ (300 gf) was employed over a loading time of $15 \mathrm{~s}$ to create indents in polished surfaces of the $\mathrm{TiB}_{2} / \mathrm{Ti}-6 \mathrm{Al}-4 \mathrm{~V}$ composite deposited samples.

\section{Results and Discussion}

\subsection{Morphology and Microstructure of Deposited Composites}

Figure 3 shows SEM images of the TiB 2 Ti-6Al-4Vcomposite bead cross sections obtained from the blown powder additive manufacturing process. All the composite beads were 
observed to be dense and metallurgically bonded to the Ti-6Al-4V substrate, with an appreciable melt depth range of $230-360 \mu \mathrm{m}$. Cracks were not prevalent and no delamination was observed for any of the composite beads on the plates. Few pores were observed especially near the clad-substrate interface for some of the clad sections which is suggested to be due to gas entrapment during processing. Dark spots were observed in the cross section micrographs, mostly at the bead edge region and their presence was observed to decrease with increasing traverse speed (reduced material delivery per unit length). These spots were identified as unmelted or partially melted particles which are presumably transported towards the edge of the bead formed as a result of Maragoni flow convection in the melt pool during processing before solidification occurs.

Figure 4 shows the XRD spectra for the $\mathrm{TiB}_{2} / \mathrm{Ti}-6 \mathrm{Al}-4 \mathrm{~V}$ composites deposited at variable laser power and constant traverse speed of $200 \mathrm{~mm} / \mathrm{min}$. Phases identified in the composite beads were $\alpha-\mathrm{Ti}, \mathrm{TiB}$ and $\mathrm{TiB}_{2}$. The $\mathrm{TiB}_{2}$ peaks have low intensity and more noticeable in the spectrum obtained from the composite processed with a laser power of $1400 \mathrm{~W}$ corresponding to an energy density of $172.5 \mathrm{~J} . \mathrm{mm}^{-2}$. The TiB phase identified in the spectra is considered as a reaction product resulting from the processing of the $\mathrm{TiB}_{2} / \mathrm{Ti}-6 \mathrm{Al}-4 \mathrm{~V}$ feedstock. The highest peak in all the spectra was found at $2 \theta=40.2^{\circ}$ which was the reflection of $\alpha$-Ti (101) phase.

Figure 5 shows the low and high magnification SEM micrographs of the central region of the $\mathrm{TiB}_{2} / \mathrm{Ti}-6 \mathrm{Al}-4 \mathrm{~V}$ composite beads produced using varying laser power with traverse speed and powder feed rate kept at $400 \mathrm{~mm} / \mathrm{min}$ and $10 \mathrm{~g} / \mathrm{min}$ respectively. The microstructure is characterised as a dendritic Ti-rich primary phase (dark background) and eutectic-like precipitates of white TiB needles formed the interdendritic regions. The dendritic Ti-rich phase is more obvious in Figure $5 \mathrm{~b}$ than in Figures $5 \mathrm{~d}$ and $5 \mathrm{f}$. This is attributed to rapid cooling and solidification associated with processing at lower energy density owing to laser power employed. The randomly oriented, whitish TiB reinforcements in the Ti matrix have high aspect ratio (length to width ratio), and their lengths are highly randomised in all the sample micrographs. Elemental constituent mixing and diffusion are expected during the laser processing which promotes boron diffusion in different direction, thus making TiB needles to grow in all those different directions. Prior to cooling and solidification, the continuous growth of the TiB needles is expected provided heat energy in the melt pool is sufficient for the growth to proceed as boron diffuses. This may suggest that the length of the in-situ synthesized $\mathrm{TiB}$ reinforcements could be dependent on the energy density employed during feedstock processing.

Figure 6 shows higher magnification SEM micrographs of the composite beads. The back ground Ti phase is characterised as acicular $\alpha$-Ti (transformed $\beta$ ) martensitic structure [20], as $\alpha$-Ti laths (light grey) were observed in the dark grey $\beta$-Ti phase (Figure $6 a$ ). This microstructure is similar to that of the partially melted Ti-6Al-4V particles seen in the composite bead cross sections. Few partially dissolved $\mathrm{TiB}_{2}$ particles were identified in the micrographs irrespective of the laser power employed during feedstock processing. This supports the low intensity peaks of $\mathrm{TiB}_{2}$ phase identified in the XRD spectra in Figure 3. TiB needles were observed at the edges of the $\mathrm{TiB}_{2}$ particles (Figures $6 \mathrm{~b}$ and $6 \mathrm{~d}$ ). This suggests the growth of $\mathrm{TiB}$ needles from the $\mathrm{TiB}_{2}$ particle edges as boron diffusion into the Ti melt 
occurs during processing. Presumably, a large number of the $\mathrm{TiB}_{2}$ particles have dissolved into the molten Ti during processing which had resulted in a large number of TiB needle precipitates observed generally in Figure 5. Few micro pores with white halo edges which are either of circular or elliptical morphology were observed in the micrographs (Figure 6d). The diameter of a typical near circular pore is measured to be $1 \mu \mathrm{m}$, which relatively coincides with the width of a typical TiB needle. This suggests that the pore-like features with whitish halo edges are the cross sections of the TiB needle precipitates in the Ti matrix.

\subsection{Hardness evaluation}

Figure 7 shows the variation of hardness across the central region of the $\mathrm{TiB}_{2} / \mathrm{Ti}-6 \mathrm{Al}-4 \mathrm{~V}$ composite beads shown in Figure 3. The Vickers hardness test was conducted using a load of $2.94 \mathrm{~N}$ (300 gf) and a loading time of $15 \mathrm{~s}$ with a schematic of how the measurement was taken. High mean hardness values which ranged between $490-590 \mathrm{HV}_{0.3}$ were measured at the top region close to the edge of the composite beads in all samples when compared to the hardness of the central region. This is attributed to the presence of partially melted $\mathrm{TiB}_{2}$ particles (Figure 3) which were likely transported by convective forces during processing to the periphery region of the clad. These $\mathrm{TiB}_{2}$ particles with the reaction product $\mathrm{TiB}$ needles increase the hardness of the top region while the central region relied more on the precipitation hardening of the $\mathrm{Ti}$ matrix by the TiB needles [14]. Moreover, it was observed that the hardness in the top region decreases with increasing laser power. A mean hardness of $590 \pm 49 \mathrm{HV}_{0.3}$ was observed when a laser power of $1400 \mathrm{~W}$ was employed, while $490 \pm 14 \mathrm{HV}_{0.3}$ was measured at the top region for composite beads produced with a laser power of $1800 \mathrm{~W}$ with a common traverse speed of $200 \mathrm{~mm} / \mathrm{min}$. This suggests that with increasing energy density as a result of higher laser power employed during processing, microstructural homogeneity with prevalent presence of uniformly distributed and randomly oriented TiB needles and decrease in partially melted $\mathrm{TiB}_{2}$ particles in composite beads could be guaranteed through process optimisation.

Considering the entire clad region, the hardness result obtained for composite beads processed with a higher traverse speed of $400 \mathrm{~mm} / \mathrm{min}$ shows a better consistency with values between $440-480 \mathrm{HV}_{0.3}$ and standard error less than 15 when compared to deposits with lower traverse speed employed for their processing. This is attributed to lower material delivery per unit length achieved when higher traverse speed is employed which allowed majority of the $\mathrm{TiB}_{2}$ particles to experience an intense spatial laser beam irradiation. This promotes near-complete to full dissolution of these particles in the melt pool to result in the formation of the TiB needles which consistently reinforce the matrix with reduced presence of partially dissolved $\mathrm{TiB}_{2}$ particles in the beads. There was a transition of hardness to values less than $400 \mathrm{HV}_{0.3}$ as indents were made in the heat affected zone (HAZ) which was not more than $0.5 \mathrm{~mm}$ deep into the substrate after the fusion zone. The substrate hardness of $350 \mathrm{HV}_{0.3}$ was measured and it was consistent with values quoted for wrought Ti-6Al-4V in the literature [21], however the hardness of laser deposited Ti-6Al-4V was reported to be higher at about $450 \mathrm{HV}$ owing to rapid cooling and solidification which resulted in a martensitic microstructure [22].

\subsection{Discussion}

The experimental observations made in this study can be explained by considering the series 
of events that occurred during the cladding process. As the feedstock is ejected into the melt pool, the particles experience irradiation as they travel through the laser beam focused on the substrate as schematically illustrated in Figure 8. The laser irradiation raises the surface temperature of these particle and this temperature, $\mathrm{T}$, attained is dependent on some parameters as indicated in equation (1) $[23,24]$.

$$
T=T_{o}+\frac{I_{(x, y)} \eta A_{p} d}{m_{p} c_{p} v_{p}}
$$

where, $T_{o}$ is the particle initial temperature, $I_{(x, y)}$ is the laser power density, $\eta$ is the particle material laser absorptivity, $A_{p}$ is the effective particle area irradiated, $d$ is the distance travelled by the particle in the laser beam, $m_{p}$ is the mass of the particle, $c_{p}$ is the specific heat capacity of the particle material, and $v_{p}$ is the particle speed. The absorption of the laser energy irradiation of the feedstock promotes rapid dissolution of the particles upon arrival in the melt pool [25]. Upon reaching the melt pool, a large number of the particles dissolve to increase the volume of the melt pool and the melt pool is stirred as a result of flow convection which is governed by the surface tension-temperature $(\gamma-T)$ gradient. However, owing to the spatial location of the particles as they travel through the laser beam during processing, some of particles may experience less irradiation, partial dissolution in the melt pool and are conveyed by the flow convection in the melt pool mostly towards the periphery (edge) of the bead composites (Figure 3). This is considered to be responsible for the presence of few partially melted particles observed in the composite microstructures.

The microstructure of the deposited composites is considered to be dependent on the melt pool chemistry and cooling rate. The melt chemistry is governed by the dissolution of the feedstock, mixing and homogenous diffusion of chemical constituents in the melt pool, while the cooling rate is governed by the temperature gradient and solidification velocity in the melt pool. In this study, the melt pool chemistry was determined with the assumption that the absolute proportion of the modified feedstock ( $10 \mathrm{wt} . \% \mathrm{TiB}_{2} / 90 \mathrm{wt} . \% \mathrm{Ti}-6 \mathrm{Al}-4 \mathrm{~V}$ ) was steadily delivered into the melt pool, fully dissolved and also with consideration of the substrate dilution in the fusion zone. The probable overall melt pool composition for composite deposited with a laser power of $1800 \mathrm{~W}, 400 \mathrm{~mm} / \mathrm{min}$ traverse speed and $10 \mathrm{~g} / \mathrm{min}$ powder feed rate (Figure 3i) was computed as 2.6 wt.\% B/97.4 wt.\% Ti as summarised in Table 2. The density of the wrought Ti-6Al-4V substrate, taken as $4.42 \mathrm{~g} / \mathrm{cm}^{3}$, and measured densities of Ti-6Al-4V and $\mathrm{TiB}_{2}$ powders as $4.439 \pm 0.003 \mathrm{~g} / \mathrm{cm}^{3}$ and $4.441 \pm 0.003 \mathrm{~g} / \mathrm{cm}^{3}$ using helium pycnometer were used in the analysis.

Neglecting the $\mathrm{Al}$ and $\mathrm{V}$ contents, the computed melt pool composition in terms of $\mathrm{Ti}$ and $\mathrm{B}$ is relatively similar to the Ti-B eutectic composition as indicated on the Ti-B binary phase diagram in Figure 9. Assuming solidification follows the Ti-B phase diagram [26], as the temperature of the melt pool temperature with $2.6 \mathrm{wt} . \% \mathrm{~B}$ decreases to about $1570{ }^{\circ} \mathrm{C}$ (point A on the liquidus line), the nucleation and growth of primary TiB precipitates are expected to start in the Ti rich solution. As this happens, the composition and temperature of the melt pool moves from point $\mathrm{A}$ to $\mathrm{C}_{\mathrm{E}}$ (eutectic point) along the liquidus line. At eutectic temperature $\left(1540{ }^{\circ} \mathrm{C}\right)$, the liquid transforms into the two solid phases (eutectic TiB and $\beta$ - 
Ti). As the temperature drops below the beta-transus temperature $\left(884^{\circ} \mathrm{C}\right)$, the $\beta$-Ti is transformed to $\alpha$-Ti. Thus, the expected the microstructure is a small fraction of primary TiB dispersed in a $(\alpha-\mathrm{Ti}+\mathrm{TiB})$ eutectic matrix. However, the microstructure observed in this study is similar to the expected under equilibrium condition, as the microstructure is characterised as mainly eutectic TiB precipitates dispersed in the $\alpha-\beta$ Ti matrix. Owing to the non-equilibrium condition due rapid cooling that characterised laser processing, primary $\mathrm{TiB}$ precipitates may not have been observed in the composite microstructure, hence the formation of eutectic $\mathrm{TiB}$ is promoted in all the composite microstructure in this study.

Summarily, the microstructure of the deposited composites is characterised as eutectic TiB needles which are uniformly dispersed in $\alpha-\beta$ Ti matrix in this study. This is relatively similar to the expected microstructure according to the Ti-B phase diagram, except for primary TiB precipitates which were not observed. The presence of few partially melted $\mathrm{TiB}_{2}$ and $\mathrm{Ti}-6 \mathrm{Al}-$ $4 \mathrm{~V}$ particles observed in the near periphery of the composite beads was attributed to partial dissolution of the particles in the melt pool and conveyance by the Maragoni flow convection. The modification made to the feedstock processed by satelliting the $\mathrm{TiB}_{2}$ onto the surface of Ti-6Al-4V particles has significantly improved the microstructural homogeneity when compared to that observed in Figure 1. This agrees with the study on the cold spray deposition of simply mixed and satellited feedstocks where it was reported that the presence of the reinforcing material, TiC, was seven times that observed when simply mixed feedstock was employed [27]. The bond existing between the satellited $\mathrm{TiB}_{2}$ and $\mathrm{Ti}-6 \mathrm{Al}-4 \mathrm{~V}$ particles was strong enough to survive powder delivery. This encourages the uniform distribution of the reinforcing element as either $\mathrm{TiB}_{2}$ particles or reaction product $\mathrm{TiB}$ needles or both in the $\mathrm{Ti}$ matrix as evident in the microstructural observations in this study. The hardness of the Ti matrix is significantly enhanced by about $30 \%$ with the presence of in-situ synthesized $12-15 \mathrm{wt} . \%$ $\mathrm{TiB}$ with the modified feedstock used in this study. The laser processing of $\mathrm{TiB}_{2} / \mathrm{Ti}-6 \mathrm{Al}-4 \mathrm{~V}$ feedstock is potentially useful for surface engineering of Ti alloys against wear and surface contact deformation.

\section{Conclusion}

The additive manufacture of $\mathrm{TiB}_{2} / \mathrm{Ti}-6 \mathrm{Al}-4 \mathrm{~V}$ composites via $\mathrm{DED}$ has been successfully conducted using a modified feedstock made of fine $\mathrm{TiB}_{2}$ powder satellited onto Ti-6Al-4V particles. The satelliting modification made to the feedstock allowed a uniform blend to be delivered into the melt pool and this promoted microstructural homogeneity as compared to a simply mixed feedstock. The microstructure of the deposited composites is characterised by eutectic TiB needles randomly oriented and uniformly dispersed in the Ti matrix. The hardness of the composite was found to range between 440 - $480 \mathrm{HV}$ which resulted from the TiB reinforcement. Hence, the method proposed for preparation of feedstock with multiple constituents for AM has been found effective to prevent segregation during processing and has significant potential to develop coatings and components with uniform microstructure and properties.

\section{Acknowledgements}

The authors would like to acknowledge and thank Mr Stuart Branston for his inestimable technical contributions during the laser processing experiments. 


\section{References}

1. ISO/ASTM Standard 52900. Standard Terminology for Additive Manufacturing General Principle - Part 1: Terminology. ASTM, West Conshohocken, PA; 2015.

2. Hentschel, O, Scheitler, C, Fedorov, A, Junker, D, Gorunov, A, Haimerl, A, Merklein, M, Schmidt, M. Experimental investigations of processing the high carbon cold-work tool steel 1.2358 by laser metal deposition for the additive manufacturing of cold forging tools. Journal of Laser Applications. 2017; 29(2): 022307-(1-10).

3. Bourell, D, Kruth, JP, Leu, M, Levy, G, Rosen, D, Beese, AM, Clare, A. Materials for additive manufacturing. CIRP Annals - Manufacturing Technology. 2017; 66(2): 659681.

4. Farayibi, PK., Abioye, TE, Clare AT. A parametric study on laser cladding of Ti- 6Al$4 \mathrm{~V}$ wire and $\mathrm{WC} / \mathrm{W}_{2} \mathrm{C}$ powder. The International Journal of Advanced Manufacturing Technology. 2016; 87(9): 3349-3358.

5. Hunt, WH, Miracle, DB. Automotive applications of metal matrix composites. ed. D.B. Miracle and S.L. Donaldson. Vol. 21, ASM International, Materials Park, OH, USA; 2001.

6. Miracle, DB. Aeronautical applications of metal matrix composites. ed. D.B. Miracle and S.L. Donaldson. Vol. 21, ASM International, Materials Park, OH, USA; 2001.

7. Farayibi, PK, Folkes, JA, Clare, AT, Oyelola, O. Cladding of pre- blended Ti-6Al- 4V and WC powder for wear resistant applications. Surface and Coatings Technology. 2011; 206 (2-3): 372-377.

8. Abioye, TE, Farayibi, PK, Kinnel, P, Clare, AT. Functionally graded Ni-Ti microstructures synthesised in process by direct laser metal deposition. The International Journal of Advanced Manufacturing Technology. 2015; 79 (5-8): 843850.

9. Wang, L, Yao, J, Hu, Y, Zhang, Q, Sun, Z, Liu, R. Influence of electric-magnetic compound field on the WC particles distribution in laser melt injection. Surface and Coatings Technology. 2017; 315: 32-43.

10. Yi, H, Qi, L, Luo, J, Zhang, D, Li, H, Hou, X. Effect of the surface morphology of solidified droplet on remelting between neighboring aluminum droplets. International Journal of Machine Tools and Manufacture. 2018; 130-131: 1-11.

11. Yi, H, Qi, L, Luo, J, Li, N. Hole-defects in soluble core assisted aluminum droplet printing: Metallurgical mechanisms and elimination methods. Applied Thermal Engineering. 2019; 148: 1183-1193. 
12. Yi, H, Qi, L, Luo, J, Zhang, D, Li, N. Direct fabrication of metal tubes with high- quality inner surfaces via droplet deposition over soluble cores. Journal of Materials Processing Technology. 2019; 264: 145-154.

13. Riquelme, A, Escalera-Rodriguez, MD, Rodrigo, P, Rams, J. Laser Cladding of Insitu Al-AlN Composite on light Alloys Substrate. Key Engineering Materials. 2017; 724: 66-70.

14. $\mathrm{Hu}, \mathrm{Y}$, Ning, F, Wang, X, Wang, H, Zhao, B, Cong, W, Li, Y. Laser deposition- additive manufacturing of in situ TiB reinforced titanium matrix composites: TiB growth and part performance. The International Journal of Advanced Manufacturing Technology. 2017; 93(9-12): 3409-3418.

15. Li, M, Ma, C, Fang, A, Pei, Z. Preparation of Metal Matrix Nanocomposite Powder Using Electroless Plating. Proceedings of the ASME $201813^{\text {th }}$ International Manufacturing Science and Engineering Conference, Joint MSEC-NAMRCManufacturing USA. 2018; 2: 1-7.

16. Li, M, Fang, A, Martinez-Franco, E, Alvarado-Orozco, JM, Pei, Z, Ma, C. Selective laser melting of metal matrix composites: Feedstock powder preparation by electroless plating. Materials Letters. 2019; 247: 115-118.

17. Farayibi, PK. Laser cladding of Ti-6Al-4V with carbide and boride reinforcements using wire and powder feedstock. PhD Thesis, Department of Mechanical, Materials and Manufacturing Engineering, University of Nottingham, Nottingham, United Kingdom; 2014.

18. Farayibi PK, Abioye TE. Additive manufacture of $\mathrm{TiB}_{2} / \mathrm{Ti}-6 \mathrm{Al}-4 \mathrm{~V}$ metal matrix composite by selective laser melting. International Journal of Rapid Manufacturing. 2019; 8(3) :259-270.

19. Qin, Y. A brief description of textile fibers. Medical Textile Materials, pp. 23-42, 2016.

20. Donachie, MJ. Titanium: A Technical Guide. ASM International, Materials Park, OH 44073-0002, USA; 2000.

21. Koike, M, Greer, P, Owen, K, Lilly, G, Murr, LE, Gaytan, SM, Martinez, E, Okabe, T. Evaluation of Titanium Alloys Fabricated using Rapid Prototyping Technologies Electron Beam Melting and Laser Beam Melting. Materials. 2011; 4: 1776-1792.

22. Yan, L, Chen, X, Li, W, Newkirk, J, Liou, F. Direct laser deposition of Ti-6Al-4V from elemental powder blends. Rapid Prototyping Journal. 2016; 22 (5): 810-816.

23. Anandkumar, R, Almeida, A, Vilar, R, Ocelik, V, DeHosson, JM. Influence of powder particle injection velocity on the microstructure of $\mathrm{Al}-12 \mathrm{Si} / \mathrm{SiCp}$ coatings produced by 
laser cladding. Surface and Coatings Technology. 2009; 04 (3): 285- 290.

24. Giuliani, V, Hugo, RJ, Gu, P. Powder particle temperature distribution in laser deposition technologies. Rapid Prototyping. 2009; 15(4): 244-254.

25. Alimardani, M, Toyserkani, E, Huissoon, JP. Three-dimensional numerical approach for geometrical prediction of multilayer laser solid freeform fabrication process. Journal of Laser Applications. 2007; 19(1): 14-25.

26. Aich, S, Chandran, KS. TiB whisker coating on titanium surfaces by solid-state diffusion: Synthesis, microstructure and mechanical properties. Metallurgical and Materials Transactions A. 2002; 33 (11): 3489-3498.

27. Al-Hamdani, KS, Murray, JW, Hussain, T, Kennedy, A, Clare, AT. Cold sprayedmetal-ceramic coatings using satellited powders. Materials Letters. 2017; 198: $184-187$. 


\section{List of Figures}
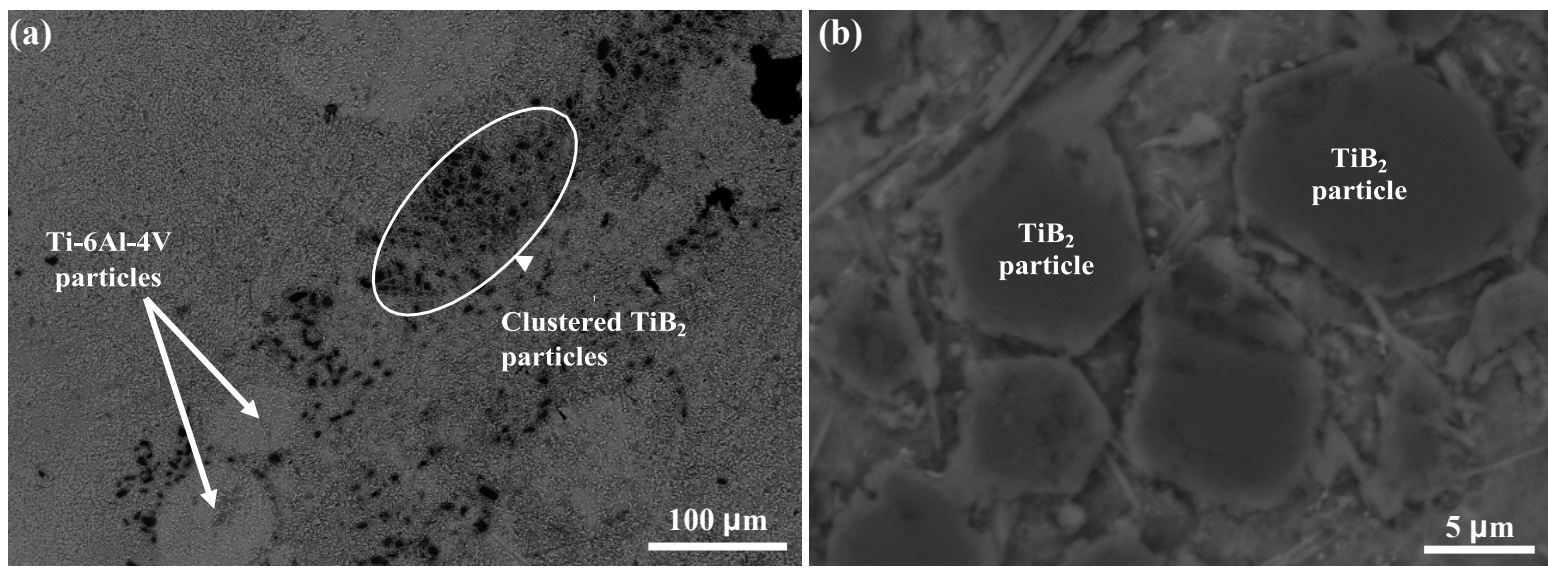

Figure 1: Microstructural inhomogeneity of laser deposited simply mixed $\mathrm{TiB}_{2} / \mathrm{Ti}-$ 6Al-4V powder feedstock. Process condition: laser power $1000 \mathrm{~W}$, traverse speed 500 $\mathbf{m m m} / \mathbf{m i n}$ and $20 \mathrm{~g} / \mathbf{m i n}$ (Source: [17]) 

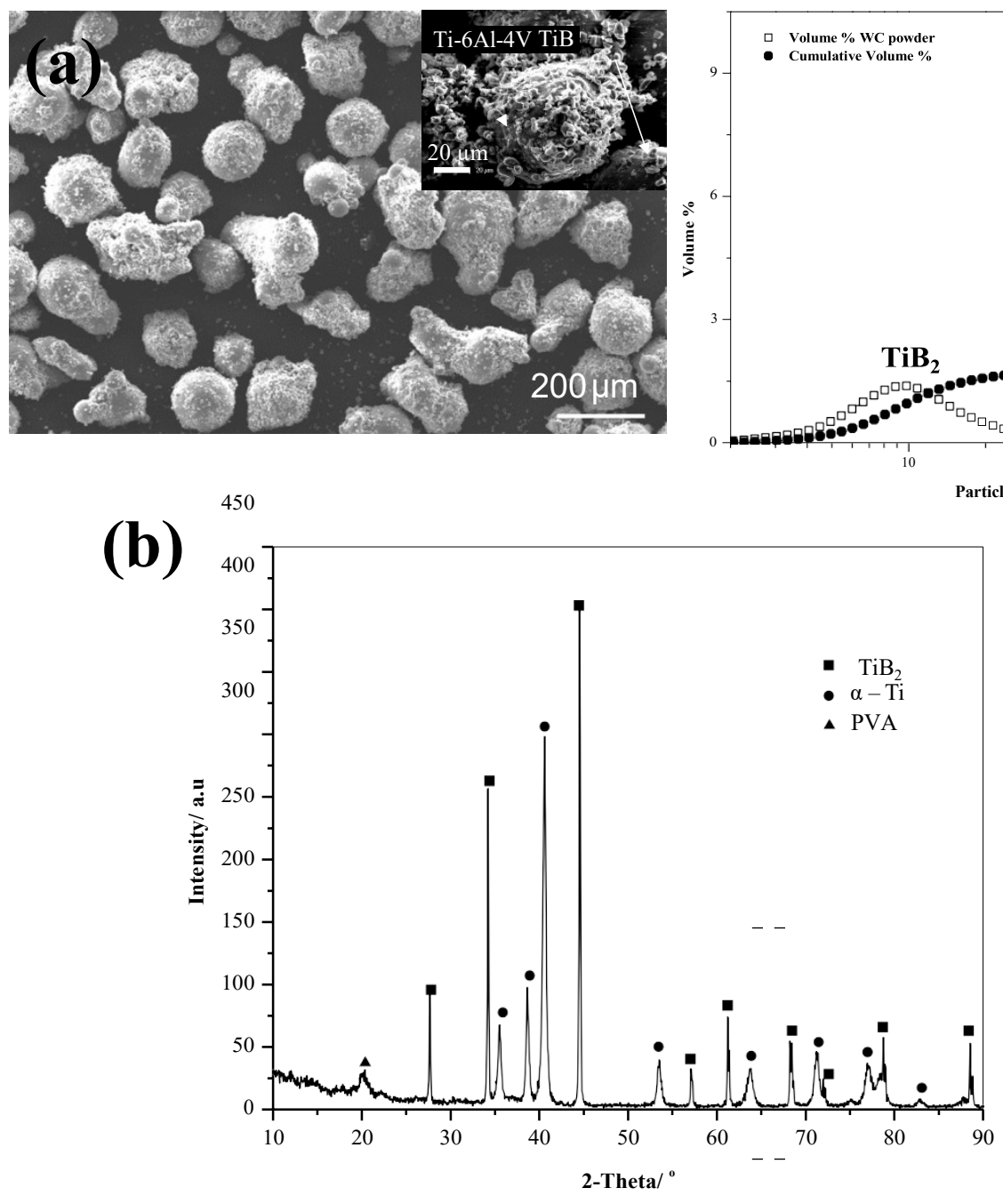

Figure 2: (a) Feedstock powder of $\mathrm{TiB}_{2}$ satellites around larger $\mathrm{Ti}-6 \mathrm{Al}-4 \mathrm{~V}$ particles with particle size curve; (b) associated $X$-Ray diffraction pattern showing $P 63 / \mathrm{mmc} \alpha$ titanium and $\mathbf{P 6} / \mathbf{m m m}$ titanium diboride. 


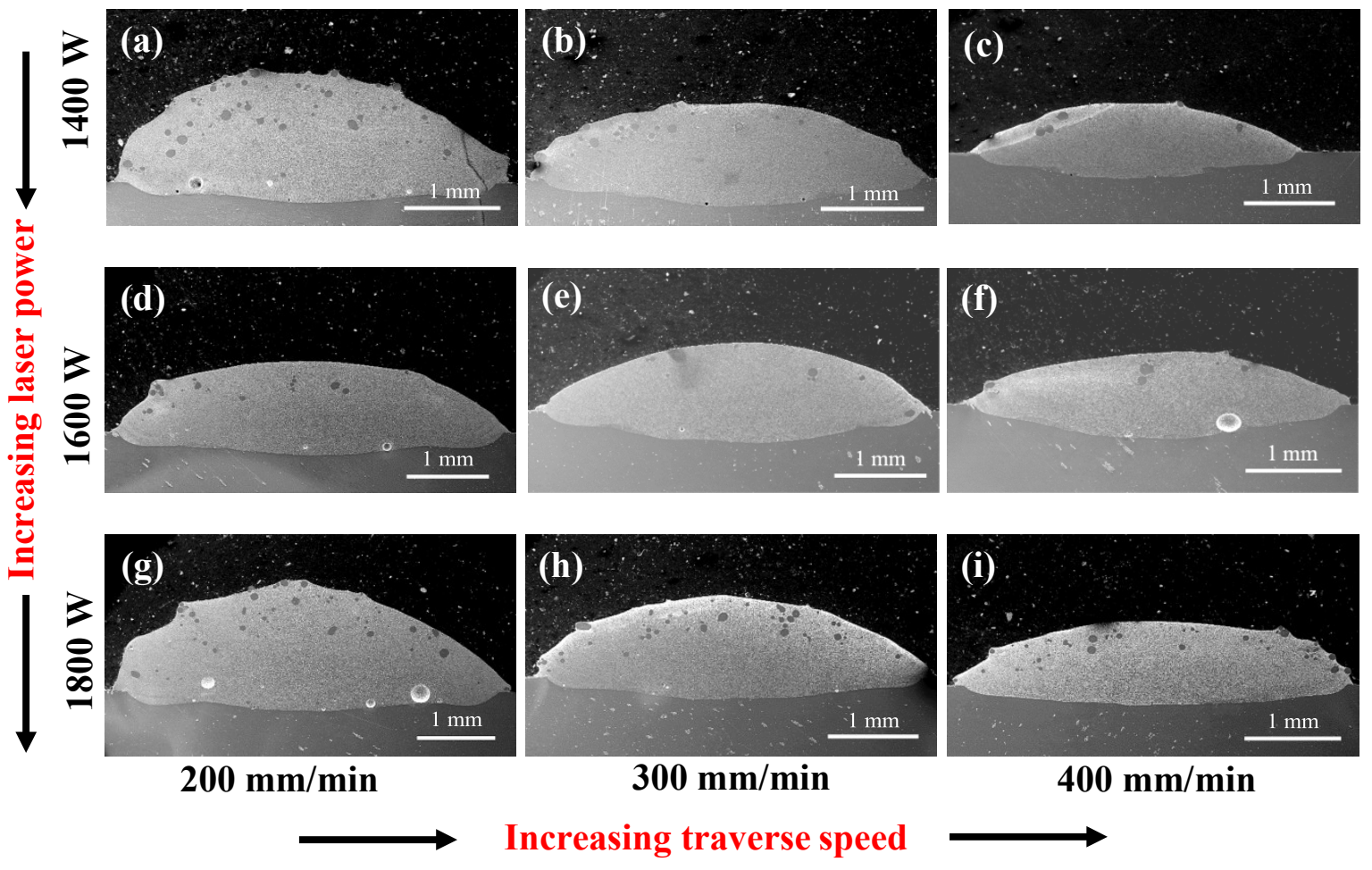

Figure 3: SEM images of the bead cross sections of $\mathrm{TiB}_{2} / \mathrm{Ti}-6 \mathrm{Al}-4 \mathrm{~V}$ composites 


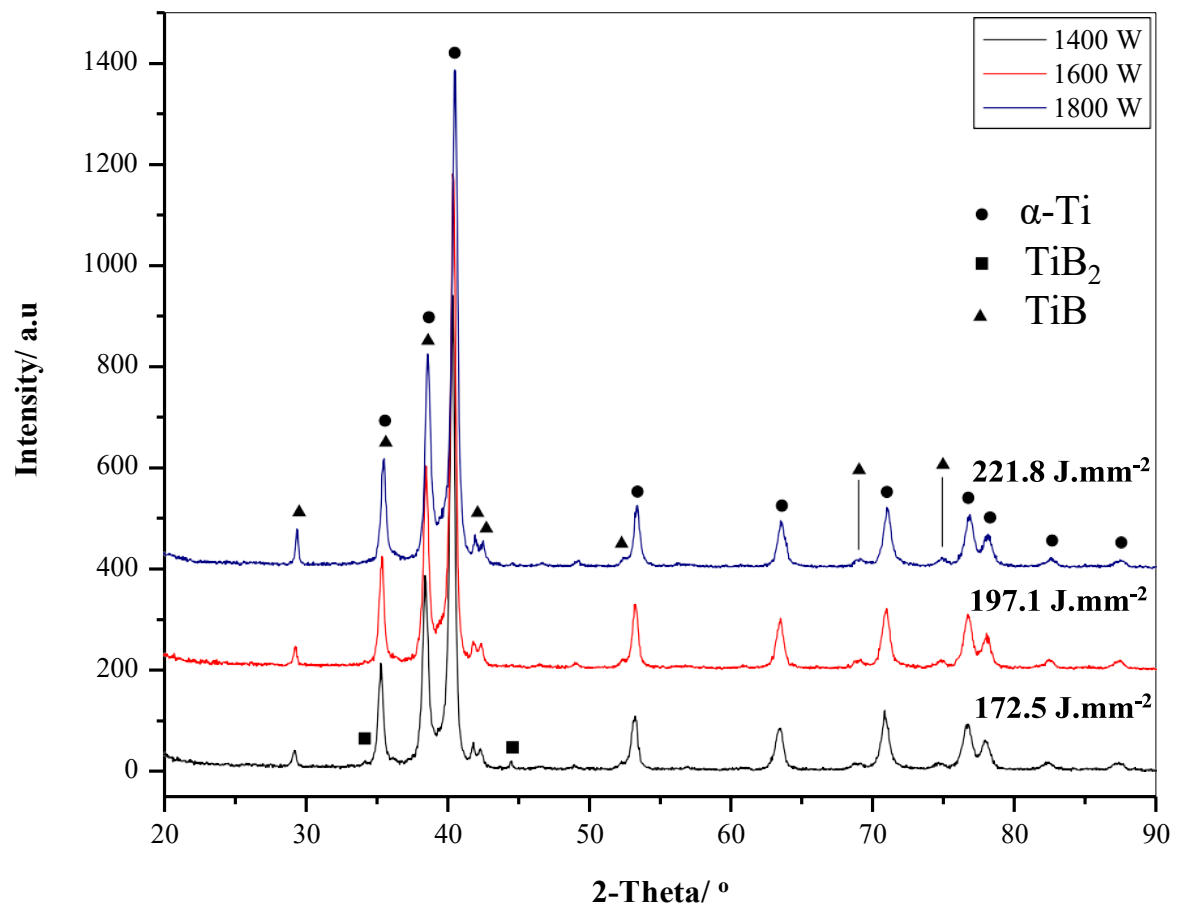

Figure 4: X-Ray diffraction patterns of $\mathrm{TiB}_{2} / \mathrm{Ti}-6 \mathrm{Al}-4 \mathrm{~V}$ composites (Figure 3 (a, d \& g)) 

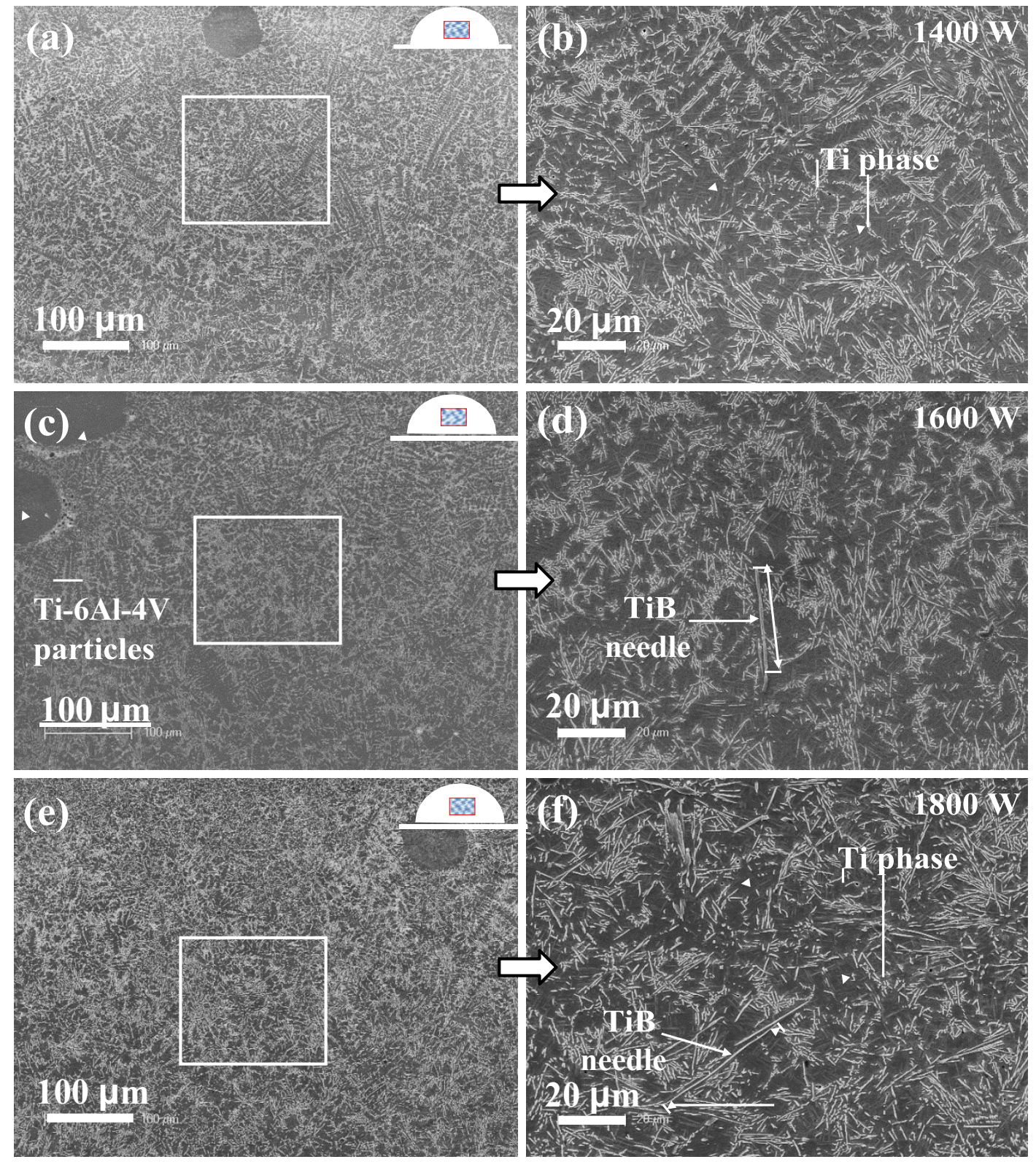

Figure 5: SE-SEM micrographs of etched samples showing a uniform distribution of TiB reinforcement randomly oriented in the central region of the clad cross sections (a) Figure 3c; (b) higher magnification of box in (a); (c) Figure 3f; (d) higher magnification of box in (c); (e) Figure 3i; and (f) higher magnification of box in (e) 

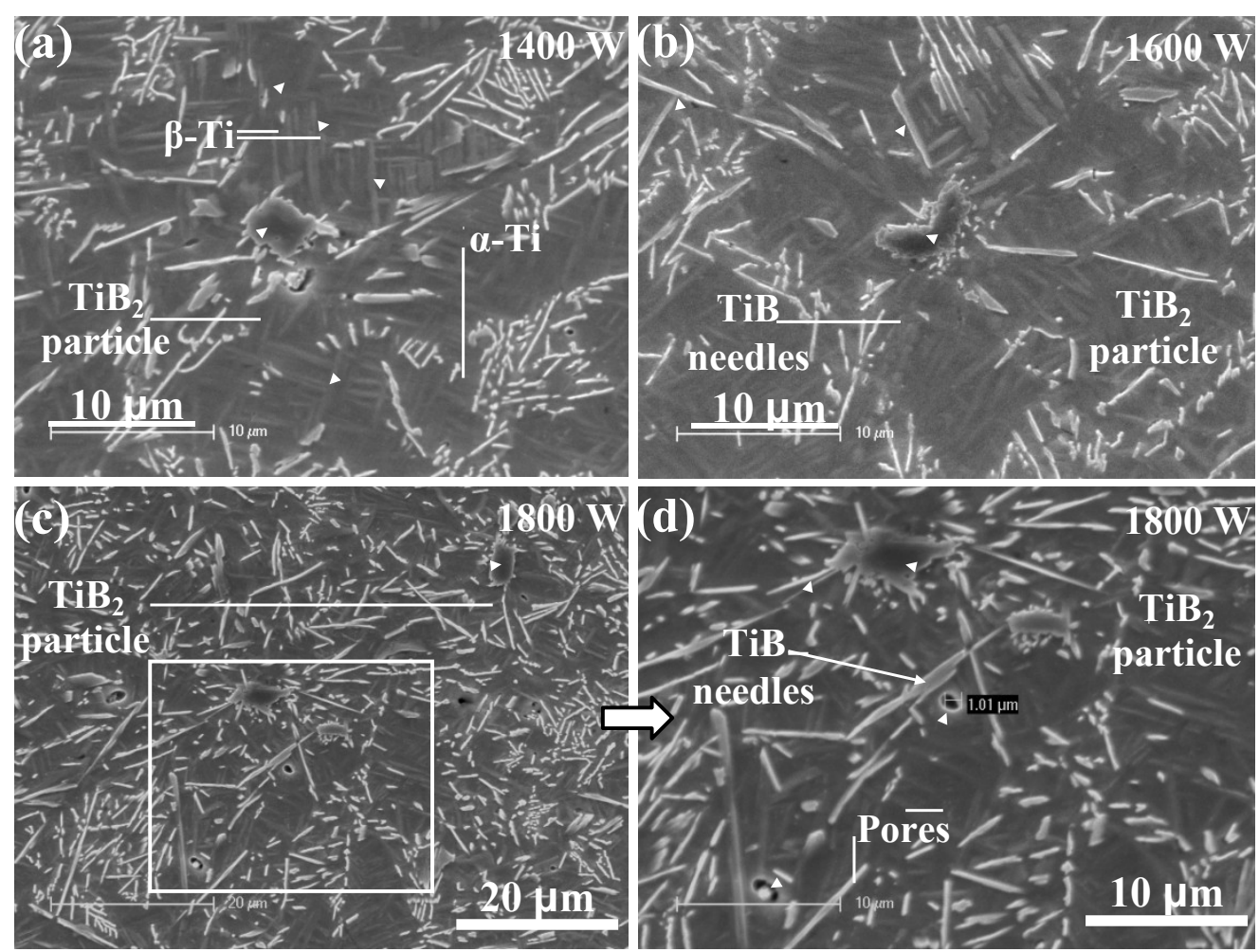

Figure 6: SE-SEM micrographs of the etched samples at higher magnification showing an acicular $\alpha$-Ti martensitic structure, randomly dispersed TiB needles and presence of partially dissolved $\mathrm{TiB}_{2}$ particles 

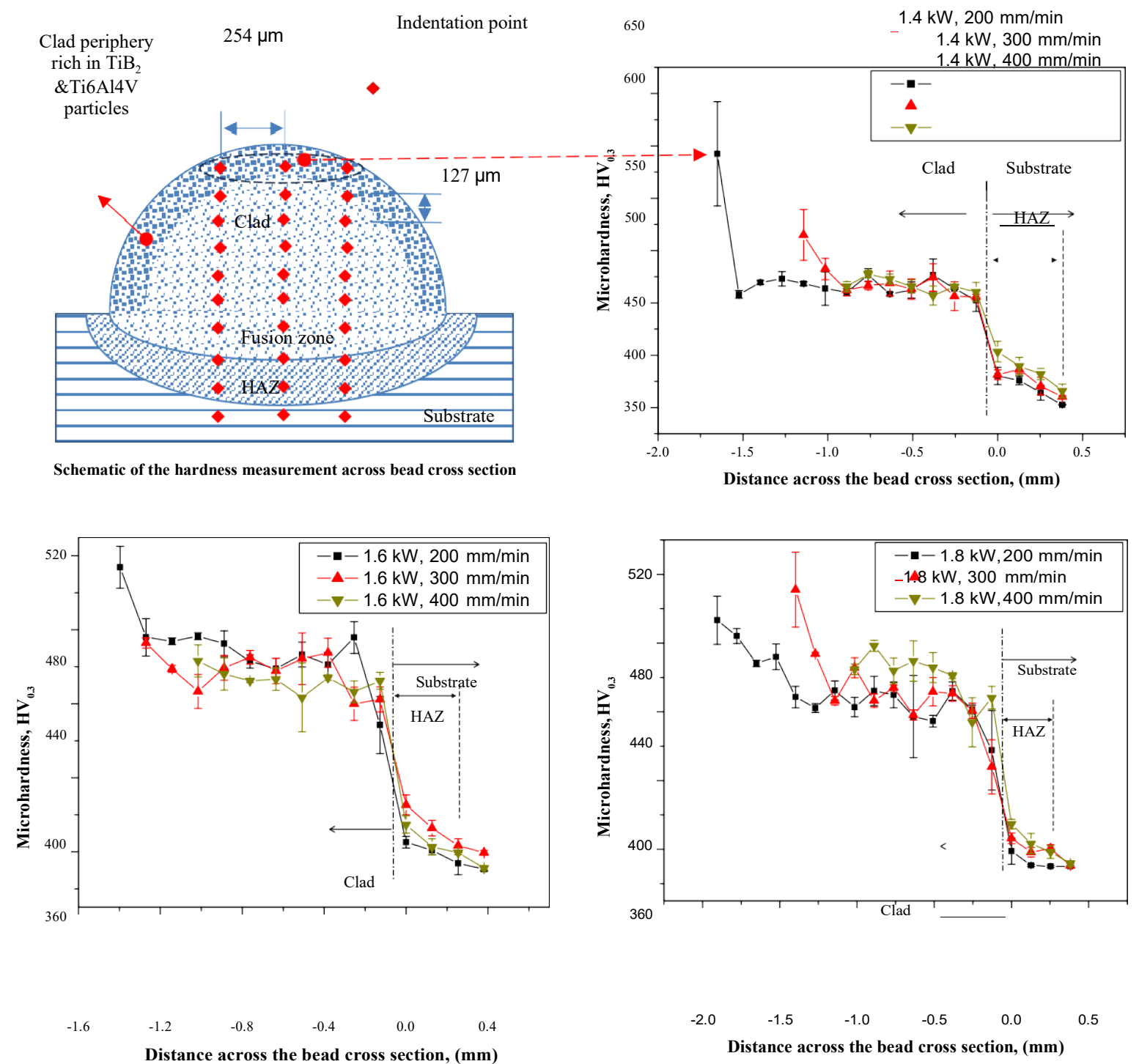

Distance across the bead cross section, $(\mathrm{mm})$

Figure 7: Hardness profiles of $\mathrm{TiB}_{2} / \mathrm{Ti}-6 \mathrm{Al}-4 \mathrm{~V}$ composites 


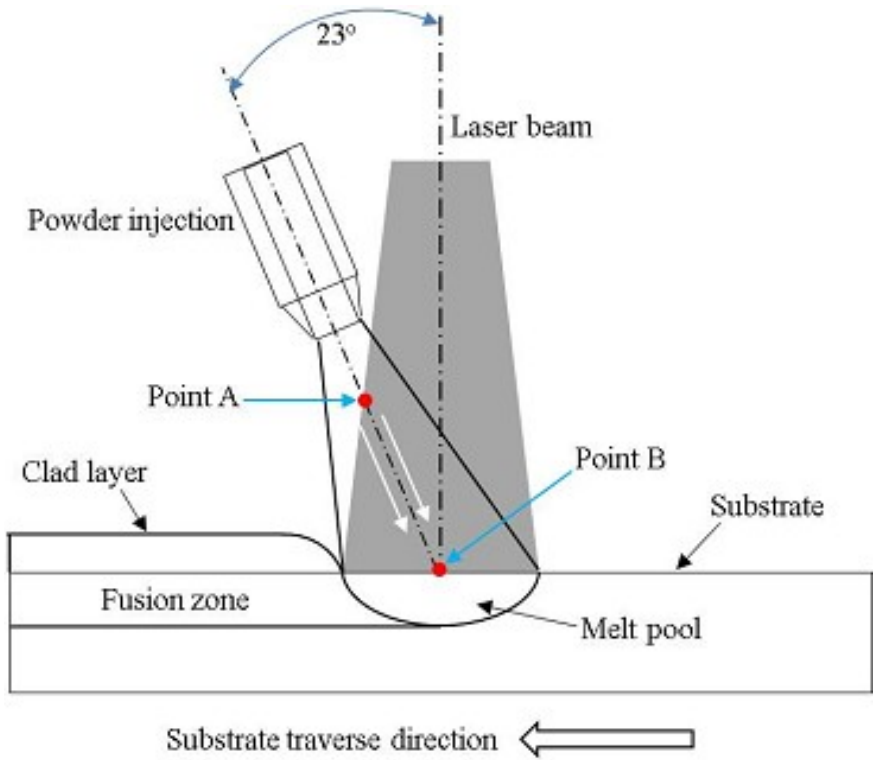

Figure 8: Interaction between laser beam and particle approaching the meltpool 


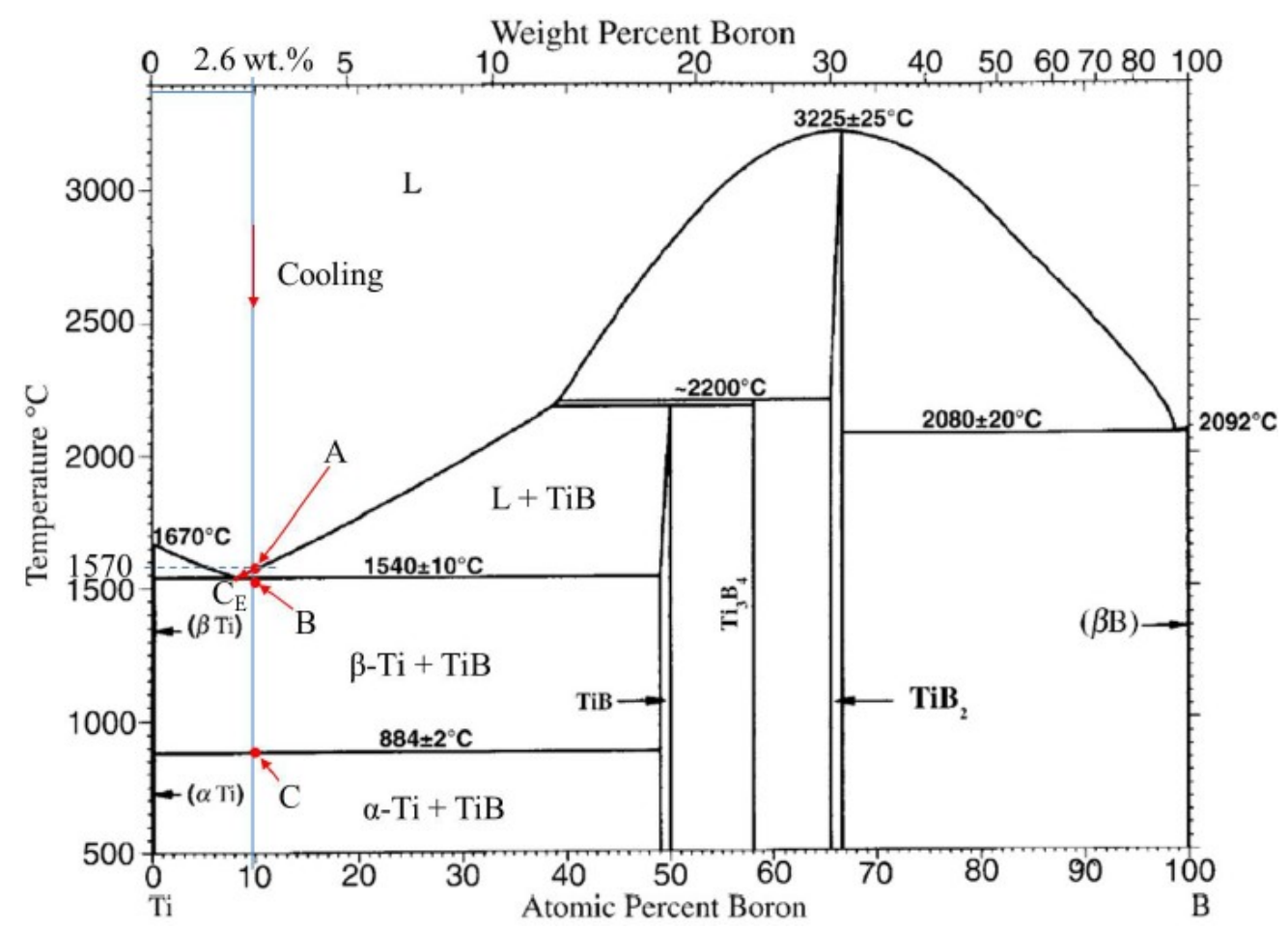

Figure 9: A plot of the probable melt pool composition (2.6 wt.\% B) on the Ti-B binary phase diagram 


\section{List of Tables}

Table 1 Processing parameters employed for blown powder deposition

\begin{tabular}{|c|c|}
\hline Parameter & Values \\
\hline Laser Power, W & $1400-1600-1800$ \\
\hline Traverse speed, mm.min & -1 \\
\hline Powder feed rate, g.min & \\
\hline Carrier gas (Ar) flow rate, $1 . \mathrm{min}^{-1}$ & $100-300-400$ \\
\hline
\end{tabular}


Table 2 Analysis for the determination of the probable overall melt pool elemental composition for composite bead with cross in Figure $3 i$

\begin{tabular}{ccccc}
\hline Element & Clad & Substrate & Total & wt.\% \\
\hline Volume $\left(\mathrm{cm}^{3}\right)$ & $2.198 \times 10^{-3}$ & $6.56 \times 10^{-4}$ & & \\
Mass $(\mathrm{g})$ & $9.756 \times 10^{-3}$ & $2.9 \times 10^{-3}$ & & \\
Ti-6Al-4V $(\mathrm{g})$ & $8.78 \times 10^{-3}$ & $2.9 \times 10^{-3}$ & $1.168 \times 10^{-2}$ & 92.29 \\
$\mathrm{TiB}_{2}(\mathrm{~g})$ & $9.76 \times 10^{-4}$ & & $9.76 \times 10^{-4}$ & 7.71 \\
$\mathrm{Ti}(\mathrm{g})$ & & & $97.36 \mathrm{wt} \% \mathrm{Ti}$ \\
$\mathrm{B}(\mathrm{g})$ & & 2.4 & $2.64 \mathrm{wt} . \% \mathrm{~B}$ \\
\hline
\end{tabular}


